\title{
Beryllium strain under dynamic loading
}

\author{
Victor Pushkov ${ }^{1,2, a}$, Alexey Yurlov ${ }^{1,2}$, Andrew Okinchits, and Tatiana Naydanova ${ }^{1}$ \\ ${ }^{1}$ Russian Federal Nuclear Center - VNIIEF, 607190, Sarov, Nizhniy Novgorod region, Russia \\ ${ }^{2}$ Sarov Physico-Technical Institute NIYaU MEPhI, 607186, Sarov, Nizhniy Novgorod region, Russia
}

\begin{abstract}
There are some data (not much) on dynamic characteristics of beryllium that are important, for example, when estimating construction performance at NPP emergencies. A number of data on stress-strain curves, spall strength, shear strength, fracture and structure responses of shock loaded beryllium have obtained in US and Russian laboratories. For today the model description of this complex metal behavior does not have a reasonable agreement with the experimental data, thus a wider spectrum of experimental data is required. This work presents data on dynamic compression-test diagrams of Russian beryllium. Experiments are performed using Hopkinson bar method (SHPB). Strain rates were $\varepsilon \sim 10^{3} \mathrm{~s}^{-1}$.
\end{abstract}

\section{Introduction}

Beryllium has an asymmetric hexagonal close-packed (hcp) lattice and has a number of unique properties: the highest (among all other metals) specific strength and heat capacity [1]. The combination of low density, high modulus of elasticity, strength and heat conductivity makes beryllium needed in aeronautical and space engineering [2]. Due to small beryllium atomic mass, small capture cross section and radiation resistance, it is one of the best materials for reflectors and moderators in nuclear engineering [2]. However, data on its mechanical properties are mainly obtained at static loading. There are some data (not much) on dynamic characteristics of beryllium that are important, for example, when estimating construction performance at NPP emergencies. A number of data on deformation curves for different types of beryllium, in particular S200F (USA) at strain rates $\dot{\varepsilon}=1500-8000 \mathrm{~s}^{-1}$ are given in $[3,4]$. For the same type of beryllium, mechanical characteristics at higher strain rates $\hat{\varepsilon}=10^{4}-10^{5} \mathrm{~s}^{-1}$ (spall strength) [4,5] as well as fracture and structure responses of shock loaded beryllium [6] are known. In [7-9] the data are given on investigation of spall and shear strength of Russian beryllium at strain rates $\dot{\varepsilon} \cdot \sim 10^{4}-10^{5} \mathrm{~s}^{-1}$ using various methods.

Researchers perform a model description of beryllium behavior under dynamic and shock-wave loading, e.g. [4-6]. For today the model description of this complex metal behavior does not have a reasonable agreement with the experimental data [4], [6], thus a wider spectrum of experimental data is required.

This investigation provides data on dynamic compression-test diagrams of Russian beryllium. Experiments are performed using Hopkinson bar method (SHPB). Strain rates were $\hat{\varepsilon} \sim 10^{3} \mathrm{~s}^{-1}$.

\footnotetext{
${ }^{a}$ Corresponding author: postmaster@ifv.vniief .ru
}

\section{Experimental}

Beryllium is prepared using the method of hot vacuum pressing [1], [7] with addition of preprepared beryllium powder. Beryllium density is $1,85 \mathrm{~g} / \mathrm{sm}^{3}$, Be content is $>98$ weight $\%, \mathrm{O}_{2} \sim 1,5$ weight $\%$, other major impurities are $\mathrm{Fe}$ and $\mathrm{C}$, and grain size is $\sim 50 \mu \mathrm{m}$.

Experiments were performed using the SHPB method at strain rates $1000-1600 \mathrm{~s}^{-1}$. The experimental setup is given in Fig. 1.

The bars were made of titanium BT-20 (Ø20 $\times$ $1500 \mathrm{~mm}$ ), samples had the size $\varnothing 10 \times 7 \mathrm{~mm}$.

\section{Results}

Figure 2 presents dynamic " $\sigma-\varepsilon$ " compression-test diagrams of Be based on experimental results. It is obvious from Figure 2 that Be has considerable strain hardening. The degree of hardening is $7,5-12,0 \mathrm{GPa} / \mathrm{rel}$. units, which is close to data in [3]. In tests 1-5 samples did not fail, the residual strain measured after tests was $\varepsilon_{\text {res }}=4,3-9 \%$.

Dynamic " $\sigma-\varepsilon$ " compression-test diagrams of Be were used to determine yield strength values presented in Table I. The yield strength dependence on strain rate was not revealed within the range of $\dot{\varepsilon}=1000-1600 \mathrm{~s}^{-1}$.

In terms of the behavior of diagrams and the values of strength yield $\sigma_{0.2}$, beryllium is very similar to preloaded $(\mathrm{P}=59 \mathrm{GPa})$ uranium [10]. However, the values $\sigma_{0.2}$ are considerably higher than in [3].

In test No. 6 at $\varepsilon=1280 \mathrm{~s}^{-1}$, the sample failed; Be strength yield was $\sigma_{6}=1490 \mathrm{MPa}$, the residual strain was $9 \%$. Failure behavior was quasi-brittle. No. 6.

Figure 3 presents a photo of the damaged sample in test

In test No. 4 the sample deformed by $\sim 7,5 \%$. The sample from test No. 4 was subjected to the secondary compression at the strain rate $\varepsilon=1150 \mathrm{~s}^{-1}$. Diagrams of Be double dynamic compression are provided in Fig. 4. In the second test the sample failed. In that case Be strength was $\sigma_{\theta}=1450 \mathrm{MPa}$.

This is an Open Access article distributed under the terms of the Creative Commons Attribution License 4.0, which permits unrestricted use, distribution, and reproduction in any medium, provided the original work is properly cited. 


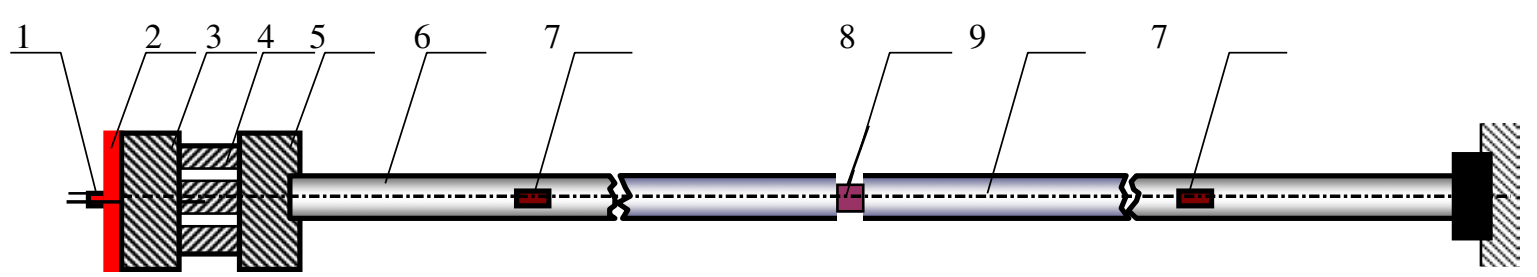

Figure 1. Experimental setup. 1,2 - HE; 3 - impactor; 4 - aluminum damper; 5 - connecter; 6 - loading bar; 7 - strain gauges; 8 - sample; 9 - support bar.

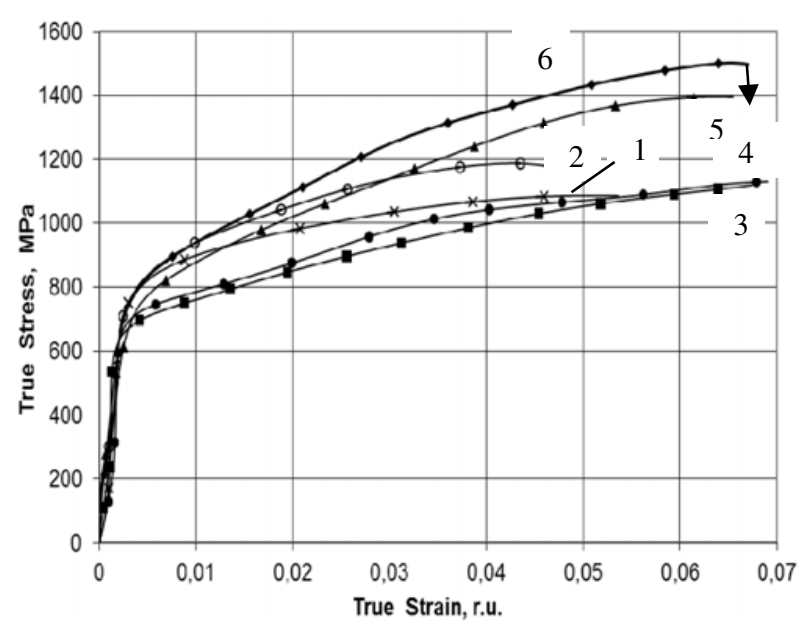

Figure 2. Be dynamic compression-test diagrams at various strain rates. $1-\hat{\varepsilon}=1600 \mathrm{~s}^{-1} ; 2-\hat{\varepsilon}=1000 \mathrm{~s}^{-1}$; $3-\dot{\varepsilon}=1550 \mathrm{~s}^{-1} ; \quad 4-\dot{\varepsilon}=1200 \mathrm{~s}^{-1} ; \quad 5-\dot{\varepsilon}=1250 \mathrm{~s}^{-1} ;$ $6-\hat{\varepsilon}=1280 \mathrm{~s}^{-1}$.

Table 1. Be yield strength values.

\begin{tabular}{|c|c|c|c|c|}
\hline $\begin{array}{c}\text { Test } \\
\text { No. }\end{array}$ & $\begin{array}{c}\text { Strain } \\
\text { rate } \\
\varepsilon, \mathrm{s}^{-1}\end{array}$ & $\begin{array}{c}\text { Yield } \\
\text { strength } \\
\sigma_{0.2}, \\
\mathrm{MPa}\end{array}$ & $\begin{array}{c}\text { Yield } \\
\text { strength } \\
\text { average value } \\
\sigma_{0.2}, \mathrm{MPa}\end{array}$ & $\begin{array}{c}\text { Yield } \\
\text { Strength } \\
\sigma_{b}, \mathrm{MPa}\end{array}$ \\
\hline 1 & 1600 & 790 & & \\
\hline 2 & 1000 & 810 & & \\
\hline 3 & 1550 & 720 & \multirow{3}{*}{$772 \pm 43$} & \\
\hline 4 & 1200 & 730 & & \\
\hline 5 & 1250 & 765 & & \\
& 1280 & 815 & & 1490 \\
\hline
\end{tabular}

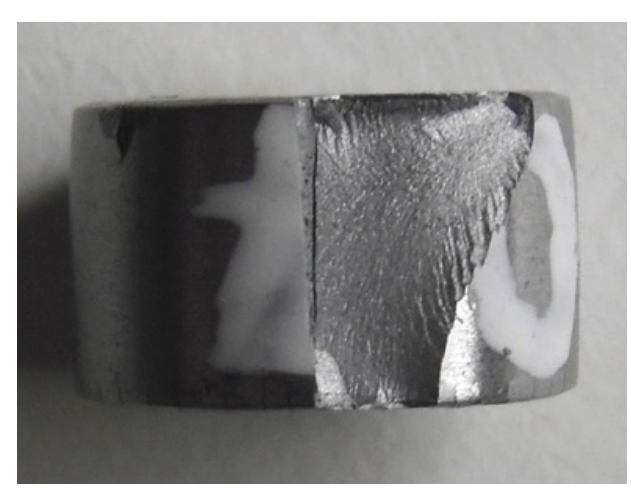

Figure 3. Fracture pattern of the sample in test No. 6.

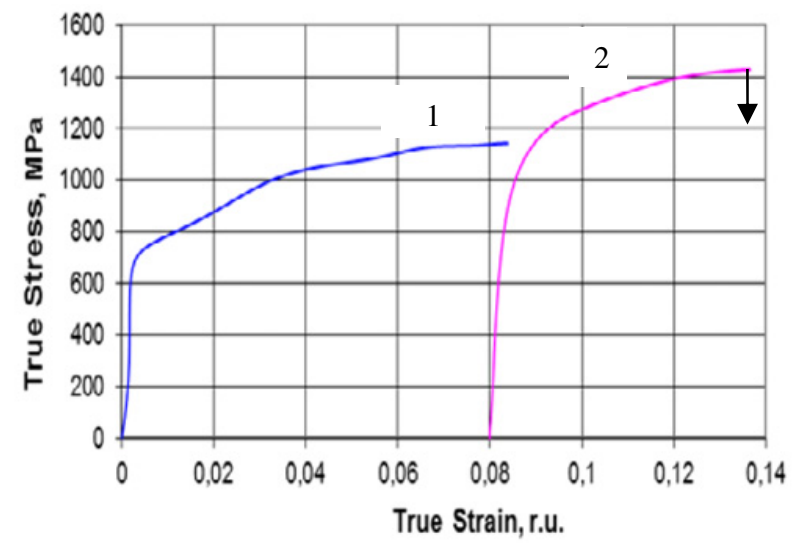

Figure 4. Diagrams of sequential double compression of beryllium at $\dot{\varepsilon}=1200 \mathrm{~s}^{-1}$ (1) and $\dot{\varepsilon}=1150 \mathrm{~s}^{-1}$ (2).

\section{Conclusion}

Using SPHB method, dynamic compression "stressstrain" diagrams of Russian beryllium were examined. Beryllium was prepared using the method of hot vacuum pressing with admixture of preprepared beryllium powder. Experiments were made at strain rates of $1000-1600 \mathrm{~s}^{-1}$. Obtained data will be useful for testing the available models of Be behavior and developing new ones which describe Be behavior under various loading, including those typical for accidents in nuclear engineering, more adequately.

\section{References}

[1] Great Soviet Encyclopedia (Rus), 3, 232-233 (Izd-vo Sovetskaya Entsiklopediya, Moscow, 1970)

[2] Great Russian Encyclopedia (Rus), 3, 365-366 (Nauchnoye Izd-vo "Great Russian Encyclopedia", Moscow 2005)

[3] W.R. Blumenthal, S.P. Abeln, D.D. Cannon, G.T. Gray III, R.W. Carpenter, Proc. SCCM 1997, 429, 411-414, American Physical Society (1997)

[4] M.B. Prime, S.R. Chen, C.D. Adams, Proc. SCCM 2011,1426, Part Two, 1035-1038, American Physical Society (2011)

[5] C.D. Adams, W.W. Anderson, G.T. Gray III, W.R. Blumenthal, C.T. Owens, F.J. Freibert, J.M. Montoya, P.J. Contreras, Proc. SCCM 2009, 1195, 509-512, American Physical Society (2009) 
[6] C.M. Cady, C.D. Adams, L.M. Hull, G.T. Gray III, M.B. Prime, F.L. Addessio, T.A. Wynn, P.A. Papin, E.N. Brown, Proc. DYMAT 2012, Freiburg, Germany, September 2-7, pp. 01009/p.1-01009/p.6, EDP Science, "The European Physical Journal", (2012)

[7] V.A. Arinin, D.V. Kryuchkov, V.A. Ogorodnikov, V.A. Raevsky, K.N. Panov, V.V. Peshkov, V.I. Skokov, O.A.Tyupanova, Proc. SCCM 2011, 1426, Part Two, 1073-1076, American Physical Society (2011)

[8] V.A. Arinin, Yu.V. Batykov, D.V. Kryuchkov, A.N. Malyshev, K.N. Panov, V.I. Skokov, Proc. XIII International Workshop "Fundamental properties of
Plutonium”, Sarov, Russia, September 9-14, 2013, p. 174, RFNC-VNIIEF (2013)

[9] E.A. Kozlov, V.I. Tarzhanov, I.V. Telichko, D.G. Pankratov, S.A. Brichikov, D.P. Kuchko, M.A. Ralnikov, A.Yu. Nikolaev, A.E. Shirobokov, Proc. XIIIInternational Workshop "Fundamental properties of Plutonium”, Sarov, Russia, September 9-14, 2013, pp. 178-180, RFNC-VNIIEF (2013)

[10] V.A. Pushkov, M.L. Andreeva, A.V. Yurlov, A.V. Kalmanov, I.V. Shiberin, Proc. XIII International Workshop "Fundamental properties of Plutonium", Sarov, Russia, September 9-14, 2013, pp. 197-199, RFNC-VNIIEF (2013) 